\title{
Heated carrier fluids in decreasing propofol injection pain: a randomized, controlled trial
}

\author{
Ann Misun Youn and Tzung-Min Hsu \\ Department of Anesthesiology and Pain Medicine, Chungnam National University Hospital, Daejeon, Korea
}

Background: Propofol is a commonly used intravenous drug during anesthetic induction because of its rapid onset and short duration. However, the injection pain that patients experience is so severe that they recall the induction of anesthesia as the most painful part of the perioperative period. Therefore, the objective of this study was to determine the effect of heated carrier fluids $\left(40^{\circ} \mathrm{C}\right)$ in decreasing propofol injection pain.

Methods: A randomized, controlled clinical trial was conducted in 90 patients aged 18 to 65 who were scheduled for either elective or urgent surgery under general anesthesia classified as American Society of Anesthesiologists physical status I or II. Patients were allocated into the following 3 groups: 1) Group W $(\mathrm{n}=30)$ who received $200 \mathrm{ml}$ of heated carrier fluids for 20 minutes prior to propofol injection; 2) Group L ( $\mathrm{n}=30)$ who received $200 \mathrm{ml}$ of heated carrier fluids for 20 minutes prior to $0.5 \mathrm{mg} / \mathrm{kg}$ 1\%lidocaine 1 minute before propofol injection; 3) Group C (control group, $\mathrm{n}=30$ ) who received $200 \mathrm{ml}$ of room temperature fluids prior to propofol injection. Pain was evaluated using verbal pain score (VPS). Results: Group W and Group L showed significant reduction $(\mathrm{P}=0.001)$ in the incidence and severity of injection pain compared to Group C. VPS scores were significantly lower in Group W and Group L compared to those of Group C. Incidence of propofol injection pain was statistically different between Group W $(P=0.005)$ and Group L $(P=0.037)$ compared to Group C, but not statistically different between Group W and Group L (P = 0.432).

Conclusions: Both sole injection of heated carrier fluids and the combination of $0.5 \mathrm{mg} / \mathrm{kg}$ 1\%lidocaine pretreatment effectively reduced propofol injection pain.

Key Words: Hot temperature, Lidocaine, Pain management, Propofol.

Corresponding author: Ann Misun Youn, M.D.

Department of Anesthesiology and Pain Medicine, Chungnam National University Hospital, 282, Munhwa-ro, Jung-gu, Daejeon 35015, Korea

Tel: 82-42-280-7840, Fax: 82-42-280-7968

Email: annyoun83@gmail.com

ORCID: http://orcid.org/0000-0001-5491-5888

Received: June 17, 2016.

Revised: August 25, 2016 (1st); September 26, 2016 (2nd).

Accepted: September 30, 2016.

Korean J Anesthesiol 2017 February 70(1): 33-38

https://doi.org/10.4097/kjae.2017.70.1.33

\section{Introduction}

Rapid onset, short duration, easy titration, and remarkable safety profile makes propofol one of the most popular intravenous anesthetic drugs used today. However, its analgesic effects are poor. In addition, pain on injection tend to be so severe that up to $80 \%$ of patients recall the incident [1]. This pain is known to be resulting from direct irritation of peripheral nerve endings on the intima of blood vessels [2] and the activation of the plasma kinin cascade with release of bradykinin which induces venodilation and hyperpermeability, thus increasing contact with aqueous propofol and free nerve endings [3].

Among numerous reports in efforts to decrease propofol injection pain, the most effective combination of drug and nondrug intervention based on a quantitative systematic review has

(c) This is an open-access article distributed under the terms of the Creative Commons Attribution Non-Commercial License (http://creativecommons.org/ licenses/by-nc/4.0/), which permits unrestricted non-commercial use, distribution, and reproduction in any medium, provided the original work is properly cited. 
been revealed to be pretreatment with lidocaine in combination with a tourniquet for venous occlusion [4]. Non-drug interventions include the use of the antecubital vein, central venous catheter, cooling or heating propofol, local cooling, and changing concentrations of free propofol by modifications of injected solutions [3,5-8]. Drug interventions include combination of nicardipine and lidocaine, iontophoretically applying lidocaine, dexmedetomidine, ketamine, and dexamethasone [1,9-12]. Nicorandil, a vasodilatory drug for treating angina, can reduce propofol injection pain from $77 \%$ in the control group to $30 \%$ in the study group [13]. The use of the antecubital vein instead of the dorsal vein of the hand for injection has been found to be the most effective non-drug intervention due to its larger diameter and faster flow rate while minimizing contact of propofol with the endothelial wall with more blood available acting as a buffer [14]. Slowing the rate of injection has been reported to cause more discomfort [3].

Unfortunately, the majority of these reports conclude that a single method is insufficient in eliminating propofol injection pain. Studies investigating the effects of propofol at various temperatures have been carried out. However, no previous study has demonstrated the contribution of hyperthermia associated venodilation in reducing propofol injection pain. Interestingly, thermal stimulus below $43^{\circ} \mathrm{C}$ with a low risk of causing burn [15] is known to be an effective venodilating technique among nurses [16] to increases both cutaneous blood flow and venodilation [17] for peripheral intravenous cannulation. This nonpharmalogical intervention has the advantage of being safe and noninvasive. In addition, it has minimal risks of burn injury compared to direct skin warming or forced air warming. Based on previous findings, we carried out a prospective, randomized, and controlled trial to test the hypothesis that warming the dorsal vein prepared for injection with intravenous carrier fluids heated to approximately $40^{\circ} \mathrm{C}$ would increase blood flow and venodilation while minimizing contact of propofol with the endothelial wall, thus decreasing injection pain. Another objective was to determine if heated carrier fluids would enhance the effect of lidocaine injected prior to propofol to decrease injection pain.

\section{Pilot study}

Prior to this study, we performed a pilot study in 80 patients with four different types of known and unknown methods to alleviate propofol pain. We also tested temperature change of the heated carrier fluids and room temperature fluids after 20 minutes, tympanic temperatures, and skin temperatures to make sure that patients were not subjected to burn injury. Temperature of carrier fluids were measured with a digital temperature probe (Brannan Digital Thermometer, Cleator Moor, England).
Tympanic temperatures were measured with a tympanic thermometer (Braun Thermoscan Ear Thermometer, Kronberg, Germany). Skin temperatures were measured with a skin temperature probe (DATAQ instruments, DI-1000tc series revision A, Akron, OH, USA).

All patients were questioned on verbal pain score (VPS) after injection of $25 \%$ of $2 \mathrm{mg} / \mathrm{kg}$ propofol. Group $\mathrm{T}(\mathrm{n}=30)$ tested the efficacy of the tourniquet method (pretreatment with 0.5 $\mathrm{mg} / \mathrm{kg} 1 \%$ lidocaine in combination with a tourniquet for venous occlusion), in which 26 patients perceived no pain (VPS grade 0 ). Group $\mathrm{H}(\mathrm{n}=10)$ received $200 \mathrm{ml}$ of warm carrier fluids heated to $40^{\circ} \mathrm{C}$ for approximately 20 minutes, in which 6 patients perceived no pain. Group L $(\mathrm{n}=30)$ was given $0.5 \mathrm{mg} / \mathrm{kg} 1 \%$ lidocaine 30 seconds prior to propofol, in which 14 patients were pain free. We instituted a fourth method, Group HL $(n=10)$, in which heated $0.5 \mathrm{mg} / \mathrm{kg} 1 \%$ lidocaine $\left(41^{\circ} \mathrm{C}\right)$ was given prior to propofol, in which all patients complained of severe pain, and so this method was not further pursued.

Initial temperature of each carrier fluid was measured with a digital temperature probe, which did not surpass $41^{\circ} \mathrm{C}$ or fall below $40^{\circ} \mathrm{C}$ after 20 minutes. The initial temperature of room temperature fluids was approximately $23-24^{\circ} \mathrm{C}$ before and after 20 minutes. There were also no tympanic or skin temperature changes after the administration of $200 \mathrm{ml}$ of heated carrier fluids. Therefore, we did not further pursue the measurement of skin temperatures in the main study. However, we included tympanic membrane temperatures in the demographic data.

\section{Materials and Methods}

\section{Materials}

After obtaining approval from the ethics committee of Chun-

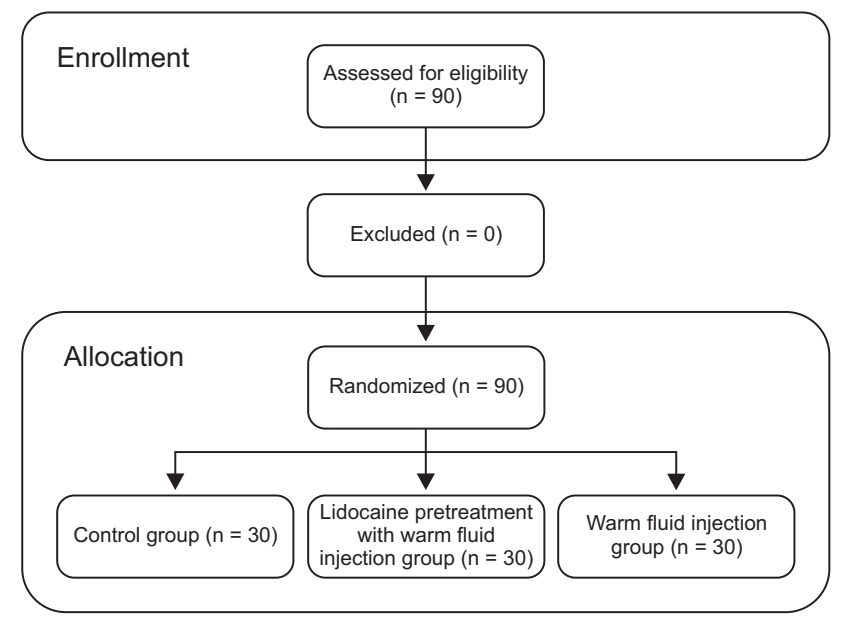

Fig. 1. Flow chart of the study design and patient groups. 
gnam National University Hospital and receiving informed consent from patients, 90 patients aged 18 to 65 classified as American Society of Anesthesiologists physical status I or II scheduled to undergo either elective or urgent surgery under general anesthesia were enrolled in this study (Fig. 1). Institutional Review Board approval was obtained before the study was conducted. Exclusion criteria included those who were pregnant and breastfeeding, pediatrics, patients with cardiovascular, renal, hepatic diseases, patients with neurological deficits, patients with psychiatric diseases, patients with difficulty in communication, patients with known anaphylaxis or allergies to local anesthetics, patients with skin damage or erythema, edema, or with concomitant use of topically applied analgesics on the study limb were excluded as well. Patients who were on low-dose aspirin and/or clopidogrel were also excluded.

\section{Method}

Patients were randomly allocated into three groups. Group $\mathrm{W}$ was given $200 \mathrm{ml}$ of heated carrier fluids $\left(40^{\circ} \mathrm{C}\right)$ prior to $25 \%$ of $2 \mathrm{mg} / \mathrm{kg}$ 1\%propofol injection. Group L was given $200 \mathrm{ml}$ of warm carrier fluids prior to $0.5 \mathrm{mg} / \mathrm{kg} 1 \%$ lidocaine pretreatment and $25 \%$ of $2 \mathrm{mg} / \mathrm{kg} \mathrm{1 \% propofol} \mathrm{injection.} \mathrm{Group} \mathrm{C} \mathrm{was}$ given $200 \mathrm{ml}$ of room temperature fluids prior to $25 \%$ of $2 \mathrm{mg}$ / $\mathrm{kg} 1 \%$ propofol injection (control group). Temperature of the heated carrier fluid was measured each time before its use to make sure it was within acceptable limits $\left(40.0-40.9^{\circ} \mathrm{C}\right)$. We limited the amount of fluids to $200 \mathrm{ml}$ to exclude vasodilation from preload effects of functional intravascular volume [18]. All measurements were performed at room temperature of the operating room $\left(23-24^{\circ} \mathrm{C}\right)$ with humidity of $35-40 \%$.

All patients were premedicated with $0.2 \mathrm{mg}$ glycopyrrolate before anesthetic induction. Electrocardiogram, heart rate (HR), pulse oximetry $\left(\mathrm{SpO}_{2}\right)$, and noninvasive mean blood pressure (MBP), were measured before anesthetic induction. An $18 \mathrm{G}$ needle was inserted the night before surgery to prevent dehydration. The site of IV access was limited to either the right or left dorsum of the hand. Before anesthetic induction, all three groups received $200 \mathrm{ml}$ of carrier fluids for 20 minutes. Only Group L received a bolus of $0.5 \mathrm{mg} / \mathrm{kg} 1 \%$ lidocaine 1 minute before propofol injection. At induction, $25 \%$ of $2 \mathrm{mg} / \mathrm{kg} 1 \%$ propofol, a dose known to induce injection pain without losing consciousness, was administered to patients before asking their VPS on a $0-3$ grade $(0=$ none, negative response to questioning; $1=$ mild pain, pain responding to questioning only, without any behavioral signs; 2 = moderate pain, pain responding to questioning and accompanied by a behavioral sign, or pain reported simultaneously with a behavioral sign, or pain reported simultaneously with a behavioral sign, but without questioning; 3 = severe pain, strong vocal response or response accompanied by facial grimacing, arm withdrawal, or tears). After questioning, the remainder of propofol ( $75 \%$ of $2 \mathrm{mg} / \mathrm{kg}$ ) was administered to complete anesthetic induction and rocuronium $0.6 \mathrm{mg} / \mathrm{kg}$ was administered for neuromuscular blockade after loss of eyelash reflex. Anesthesia was maintained with 1 MAC desflurane and $50 \%$ oxygen with air. Remifentanil was continuously infused after measuring vital signs and propofol injection to optimize intubation conditions. Changes in vital signs were measured before anesthetic induction (MBP $1, \mathrm{HR} 1, \mathrm{SpO}_{2} 1$ ), after injection of propofol $2 \mathrm{mg} / \mathrm{kg}$ (MBP 2, $\mathrm{HR} 2, \mathrm{SpO}_{2} 2$ ), and immediately after intubation (MBP 3, $\mathrm{HR} 3, \mathrm{SpO}_{2} 3$ ). Body temperatures initially (BT 1) and after intubation (BT 2) were also recorded.

\section{Data analyses}

Statistical analyses were conducted using IBM SPSS statistics software (version 20.0, IBM Corp., Armonk, NY, USA) and data expressed as mean \pm SE. The incidence of pain residing from placebos was estimated to be $80 \%$, and a $50 \%$ reduction in the group injected with the study fluid was considered to be of clinical importance. Based on an $\alpha$ error of 0.05 and a $\beta$ error of 0.2 (power $=0.8$ ), a minimum sample size was determined to be 23 patients per group (22.305 patients from the equation by Fleiss). With additional patients for attrition, 30 patients were chosen to distinguish any variance. Demographic data were compared using ANOVA and sex was compared using Pearson $\mathrm{x}^{2}$ test. The incidence and severity of propofol injection pain between the groups were compared using both $\mathrm{x}^{2}$ test and Fisher's exact test. Comparisons among the three groups were performed using Mann-Whitney test or one way ANOVA. Vital signs (MBP, HR, $\mathrm{SpO}_{2}$, and $\mathrm{BT}$ ) were compared using ANOVA. A P value of less than 0.05 was considered to be statistically significant.

\section{Results}

A total of 90 patients completed the study. Demographic characteristics (sex, age, height, weight) are shown in Table 1. The incidence and severity of propofol injection pain are sum-

Table 1. Demographic Data

\begin{tabular}{lcccc}
\hline & Group C & Group W & Group L & P value \\
\hline Sex $(\mathrm{M} / \mathrm{F})$ & $20 / 10$ & \multicolumn{1}{c}{$13 / 17$} & $17 / 13$ & 0.189 \\
Age $(\mathrm{yr})$ & $38.8 \pm 2.8$ & \multicolumn{1}{c}{$45.2 \pm 2.2$} & $42.7 \pm 2.5$ & 0.195 \\
Height $(\mathrm{cm})$ & $166.1 \pm 1.7$ & $163.1 \pm 1.4$ & $164.3 \pm 1.3$ & 0.384 \\
Weight $(\mathrm{kg})$ & $67.5 \pm 2.1$ & $60.8 \pm 1.7$ & $63.5 \pm 2.6$ & 0.091 \\
\hline
\end{tabular}

Data are expressed as mean \pm SE or number of patients. There were no statistically significant differences among the groups. Group C: control group, Group W: $200 \mathrm{ml}$ of warm carrier fluids, Group L: $200 \mathrm{ml}$ of warm carrier fluids prior to $0.5 \mathrm{mg} / \mathrm{kg} 1 \%$ lidocaine pretreatment. 
marized in Table 2. Vital trends (MBP, $\left.\mathrm{HR}, \mathrm{SpO}_{2}, \mathrm{BT}\right)$ are shown in Table 3.

The incidence of propofol injection pain was statistically different between groups. A total of 14 patients in Group W (46.7\%), 11 in Group L (36.7\%), and 4 (13.3\%) in Group C were completely free of injection pain $\left(\mathrm{P}=0.002\right.$, Pearson $\mathrm{X}^{2}$ test). The severity of propofol injection pain was also statistically different ( $\mathrm{x}^{2}$ test, $\mathrm{P}=0.002$ ) among the three groups. Six patients in Group C experienced severe pain (VPS 3) while 0 patients in Group W and 1 patient in Group L experienced severe pain. Using Fisher's exact test, Group W and Group C showed statistically significant difference $(\mathrm{P}=0.018)$ in the incidence of propofol injection pain, while Group L and Group C also showed statistically significant difference $(\mathrm{P}=0.036)$ in the incidence of propofol injection pain. There was no statistically significant difference between Group W and Group L $(P=0.3)$ in the incidence of propofol injection pain. Group $\mathrm{W}(\mathrm{P}=0.001)$ and Group $\mathrm{L}$ $(\mathrm{P}=0.001)$ showed statistically significant reduction in the incidence of propofol injection pain when compared to Group C.

Table 2. Incidence and Severity of Propofol Injection Pain

\begin{tabular}{lrrrrr}
\hline & & Group C & Group W & Group L & Total \\
\hline Grade & 0 & 4 & 14 & 11 & 29 \\
& 1 & 8 & 9 & 14 & 31 \\
& 2 & 12 & 7 & 4 & 23 \\
& 3 & 6 & 0 & 1 & 7 \\
$\mathrm{n}$ & 30 & 30 & 30 & 90 \\
\hline
\end{tabular}

Data are expressed as number of patients. There was statistically significant difference between Group W and Group C and between Group L and Group C. However, there was no statistically significant difference between Group W and Group L. Group C: control group, Group W: $200 \mathrm{ml}$ of warm carrier fluids, Group L: $200 \mathrm{ml}$ of warm carrier fluids prior to $0.5 \mathrm{mg} / \mathrm{kg} 1 \%$ lidocaine pretreatment.
However, Group W and Group L showed no statistically significant difference $\left(\mathrm{P}=0.727\right.$, Mann-Whitney test). Pearson $\mathrm{x}^{2}$ test also showed statistically significant difference in propofol injection pain between Group W ( $\mathrm{P}=0.005)$ or between Group L $(\mathrm{P}=0.037)$ compared to group $\mathrm{C}$, but no statistically significant difference $(\mathrm{P}=0.432)$ between Group W and Group L.

There were no statistically significant differences regarding demographic data. However, MBP after the injection of propofol (MBP2) in Group C was higher compared to those in the other groups $(\mathrm{P}=0.003)$.

\section{Discussion}

This present study compared the effects of heated carrier fluids in decreasing propofol injection pain. Although the methods are slightly different, our results are fairly consistent with those of other studies in which local warming or forced air warming of the intravenous site reduced propofol injection pain [19]. The assumed mechanism is that thermal stimulus increases blood flow and allows for venodilation, thus diluting propofol, letting it flow mainstream of the vascular lumen and minimize contact with vascular epithelial cells. A study examining the response of skin microvasculature on transdermally applied acetylcholine or local heating to $41^{\circ} \mathrm{C}$ to which patients are not at risk of potential burn injury has found that the former increased blood flow reaching a plateau while the latter induced dose-dependent vasodilation [20]. This implicates that vasodilation promoted by hyperthermia is more capable of inducing changes in hemodynamics, increasing blood flow rate, altering pharmacokinetics of drugs and therapeutic responses, accelerating drug injection, and increasing drug absorption [21]. Thus, propofol injection pain can be decreased by giving thermal stimulation with heated carrier fluids.

Table 3. Vital Signs

\begin{tabular}{llcccc}
\hline & & Group C $(\mathrm{n}=30)$ & Group W $(\mathrm{n}=30)$ & Group L $(\mathrm{n}=30)$ & P value \\
\hline \multirow{2}{*}{$\mathrm{MBP}$} & 1 & $91.8 \pm 1.8$ & $89.4 \pm 2.6$ & $85.9 \pm 2.2$ & 0.182 \\
& 2 & $89.1 \pm 2.7$ & $78.8 \pm 2.1$ & $80.1 \pm 1.9$ & 0.003 \\
$\mathrm{HR}$ & 3 & $104.9 \pm 4.3$ & $98.6 \pm 2.9$ & $98.3 \pm 2.9$ & 0.305 \\
& 1 & $72.9 \pm 2.6$ & $73.3 \pm 2.4$ & $68.4 \pm 2.5$ & 0.318 \\
$\mathrm{SpO}_{2}$ & 2 & $73.6 \pm 2.5$ & $76.4 \pm 2.3$ & $75.2 \pm 1.9$ & 0.675 \\
& 3 & $88.8 \pm 3.2$ & $92.9 \pm 2.5$ & $84.9 \pm 1.6$ & 0.084 \\
$\mathrm{BT}$ & 1 & $99.1 \pm 0.3$ & $99.1 \pm 0.2$ & $98.9 \pm 0.2$ & 0.641 \\
& 2 & $99.9 \pm 0.0$ & $99.9 \pm 0.1$ & $99.6 \pm 0.3$ & 0.318 \\
& 1 & $99.9 \pm 0.0$ & $100.0 \pm 0.0$ & $99.8 \pm 0.2$ & 0.483 \\
\end{tabular}

Data are expressed as mean \pm SE. There was statistically significant difference in MBP measured after propofol injection among the three groups (MBP 2). There were no statistically significant difference among the three groups regarding other vital signs (MBP: mean blood pressure, HR: heart rate, $\mathrm{SpO}_{2}$ : oxygen saturation, BT: body temperature). Group C: control group, Group W: $200 \mathrm{ml}$ of warm carrier fluids, Group L: $200 \mathrm{ml}$ of warm carrier fluids prior to $0.5 \mathrm{mg} / \mathrm{kg} 1 \%$ lidocaine pretreatment. 
The use of heat application together with local anesthetics to produce a sensory block to alleviate pain has also been reported. Warmed lidocaine injected intra-articularly reduced intraoperative and postoperative analgesia requirements [22]. Placing a heating patch on top of a topical lidocaine $70 \mathrm{mg} /$ tetracaine 70 $\mathrm{mg}$ patch to increase skin temperatures approximately $5^{\circ} \mathrm{C}$ to facilitate delivery has been reported to provide significant pain relief [23]. However, propofol injection after pretreatment with heated $0.5 \mathrm{mg} / \mathrm{kg} 1 \%$ lidocaine in our pilot study was ineffective. Although we hypothesized that heated carrier fluids would synergize with the local anesthetic's properties, analgesic effects were lower than that of sole administration of heated carrier fluids. This may be due to heating of the pretreated $1 \%$ lidocaine when injected together with heated carrier fluids. Topical lidocaine and prilocaine was reported to eliminate the initial response of rapid vasodilation [24], which may have hindered the vasodilatory effects of heated carrier fluids.

In order to estimate the appropriate time for the infusion of heated carrier fluids to achieve maximum results, we searched for reports on skin perfusion in response to heat application. Minson et al. [25] found two mechanisms independent from each other that might have contributed to the increase in skin blood flow in a biphasic manner. The first is a fast responding axon mediated reflex that causes a vasodilatory "peak," while a slower response mediated production of nitric oxide creates a vasodilatory "plateau." The second response of nitric oxide to induce vasodilation occurs approximately 20 minutes after heat application. However, further prolongation may induce sweating and vasoconstriction, which is why we decided to use a 20 minute stimulus interval.

A statistically significant temporary increase in MBP was found after the injection of propofol in the control group $(\mathrm{P}=$ 0.003). This increase is likely due to patient movement or anxiety from pain during propofol injection. This finding is inconsistent with the report that women have lower pain thresholds and tolerance to nociceptive stimulation compared to men [26] and seems to be independent of the influence of sex.

Our study has several limitations. First, we were unable to control temperature decrease of heated carrier fluids during the first 20 minutes. We were only able to make sure that the initial temperature of carrier fluids were between $40.0-40.9^{\circ} \mathrm{C}$ and that approximately $200 \mathrm{ml}$ were infused in each patient prior to propofol injection. Fortunately, within the 20 minutes of our study, temperatures of the heated carrier fluids did not fall drastically $\left(40.0-40.9^{\circ} \mathrm{C}\right)$. In addition, temperatures of the room temperature fluids did not change before infusion and after 20 minutes of injection. Second, we were unable to measure venous temperature changes or the degree of venous dilation before and after 20 minutes of injection. Temperature changes of the tympanic membrane and skin are limited in explaining the effects of heated carrier fluids because, for optimal biophysical effects extracted from heat therapy to occur, an increase of $3-4^{\circ} \mathrm{C}$ in skin temperature is needed [27]. This was not the case in our study. Statistically significant increase in median vein diameters after thermal stimulus has been noted by by Tokizawa et al. [28], which were comparable with those of van Bemmelen et al. [29], due to increase in sympathetic vasodilation [30]. Therefore, median vein diameter after thermal stimulus should be included as an important parameter in future studies. Third, switching fluids and waiting for venodilation is cumbersome and may prolong induction time, which is problematic in busy hospitals. However, intravenous warming is simple and non-invasive, without risks of burn, without affecting systemic hemodynamics. Fourth, our results were statistically significant in reducing propofol injection pain but were not superior to previously studied interventions, such as the tourniquet method. Fifth, factors such as patient mood or physical condition might have influenced study results, and these limitations must be taken into account in future studies.

Propofol injection pain still remains a major problem because its complete elimination is challenging. Despite our limitations, our study demonstrated that using heated carrier fluids is a safe, non-invasive, non-pharmacological intervention in decreasing propofol injection pain. Therefore, if the dorsal vein is the site of injection, we recommend infusing heated carrier fluids before anesthetic induction to enhance analgesic effects and reduce propofol injection pain in adjunct with other effective techniques. For example, use of the tourniquet method (pretreatment with $0.5 \mathrm{mg} / \mathrm{kg}$ lidocaine in combination with a tourniquet for venous occlusion), which is most effective in reducing propofol injection pain with heated carrier fluids for synergistic effects may be of benefit. However, such methods also need to be further researched. Additionally, the use of warm intravenous fluids with pretreatment of lidocaine needs to be further investigated by performing actual measurements of venous diameters to identify any delay or reduction in initial venodilation.

\section{Acknowledgments}

The authors would like to thank Professor Honggie Kim of Chungnam National University, Department of Information and Statistics, for his statistical expertise. 


\section{References}

1. Jeon Y. Reduction of pain on injection of propofol: combination of nitroglycerin and lidocaine. J Anesth 2012; 26: 728-31.

2. Doenicke AW, Roizen MF, Rau J, Kellermann W, Babl J. Reducing pain during propofol injection: the role of the solvent. Anesth Analg 1996; 82: 472-4.

3. Scott RP, Saunders DA, Norman J. Propofol: clinical strategies for preventing the pain of injection. Anaesthesia 1988; 43: 492-4.

4. Picard P, Tramèr MR. Prevention of pain on injection with propofol: a quantitative systematic review. Anesth Analg 2000; 90: 963-9.

5. Seki S, Sekine R, Aketa K, Kobayashi Y, Ichimiya T, Tsuchida H, et al. Induction of anesthesia with propofol injected through a central venous catheter. Masui 1999; 48: 62-6.

6. Parmar AK, Koay CK. Pain on injection of propofol. A comparison of cold propofol with propofol premixed with lignocaine. Anaesthesia 1998; 53: 79-83.

7. Terada N, Takubo I, Fujinaka W, Takatori M. Effectiveness of local cooling and lidocaine administration for prevention of pain upon injection of propofol. Masui 2014; 63: 836-40.

8. Yamakage M, Iwasaki S, Satoh J, Namiki A. Changes in concentrations of free propofol by modification of the solution. Anesth Analg 2005; 101: 385-8

9. Sadler PJ, Thompson HM, Maslowski P, Liddle A, Rowbotham DJ. Iontophoretically applied lidocaine reduces pain on propofol injection. Br J Anaesth 1999; 82: 432-4.

10. Lee JH, Jung SY, Kim MH, Cho K. The effect of dexmedetomidine on propofol injection pain. Korean J Anesthesiol 2014; 67(Suppl): S30-1.

11. Wang M, Wang Q, Yu YY, Wang WS. An effective dose of ketamine for eliminating pain during injection of propofol: a dose response study. Ann Fr Anesth Reanim 2013; 32: e103-6.

12. Kwak KH, Ha J, Kim Y, Jeon Y. Efficacy of combination intravenous lidocaine and dexamethasone on propofol injection pain: a randomized, double-blind, prospective study in adult Korean surgical patients. Clin Ther 2008; 30: 1113-9.

13. Yoshimura Y, Iwasaki T, Shimizu Y, Takasaki M. Nicorandil reduces incidence and severity of pain on propofol injection. Masui 2003; 52: 1204-6.

14. Jalota L, Kalira V, George E, Shi YY, Hornuss C, Radke O, et al. Prevention of pain on injection of propofol: systematic review and metaanalysis. BMJ 2011; 342: d1110.

15. Moritz AR, Henriques FC. Studies of thermal injury: II. The relative importance of time and surface temperature in the causation of cutaneous burns. Am J Pathol 1947; 23: 695-720.

16. Ichimura M, Matsumura Y, Sasaki S, Murakami N, Mori M. Clinical investigation of the vein dilation methods for venipuncture. Bull Fac Health Welf Sci Okayama Prefect Univ 2011; 18: 55-63.

17. Barcroft H, Edholm OG. The effect of temperature on blood flow and deep temperature in the human forearm. J Physiol 1943; 102: 5-20.

18. Yuan SY, Luo TY, Liu Z, Lin Y. Efficacy of different fluids preload on propofol injection pain: a randomized, controlled, double-blinded study. J Huazhong Univ Sci Technol Med Sci 2016; 36: 249-53.

19. Park SE, Kang K, Park SH, Cho YW, Kim CH. Effect of local warming of the injection site and forearm on propofol-induced pain. Korean J Anesthesiol 2002; 43: 687-92.

20. Christen S, Delachaux A, Dischl B, Golay S, Liaudet L, Feihl F, et al. Dose-dependent vasodilatory effects of acetylcholine and local warming on skin microcirculation. J Cardiovasc Pharmacol 2004; 44: 659-64.

21. Vanakoski J, Seppälä T. Heat exposure and drugs. A review of the effects of hyperthermia on pharmacokinetics. Clin Pharmacokinet 1998; 34: 311-22.

22. Arai YC, Ikeuchi M, Fukunaga K, Ueda W, Kimura T, Komatsu T. Intra-articular injection of warmed lidocaine improves intraoperative anaesthetic and postoperative analgesic conditions. Br J Anaesth 2006; 96: 259-61.

23. Masud S, Wasnich RD, Ruckle JL, Garland WT, Halpern SW, Mee-Lee D. Contribution of a heating element to topical anesthesia patch efficacy prior to vascular access: results from two randomized, double-blind studies. J Pain Symptom Manage 2010; 40: 510-9.

24. Wong BJ, Minson CT. Altered thermal hyperaemia in human skin by prior desensitization of neurokinin-1 receptors. Exp Physiol 2011; 96: 599-609.

25. Minson CT, Berry LT, Joyner MJ. Nitric oxide and neurally mediated regulation of skin blood flow during local heating. J Appl Physiol (1985) 2001; 91: 1619-26.

26. Cepeda MS, Carr DB. Women experience more pain and require more morphine than men to achieve a similar degree of analgesia. Anesth Analg 2003; 97: 1464-8.

27. Kankaanpää M, Taimela S, Airaksinen O, Hänninen O. The efficacy of active rehabilitation in chronic low back pain. Effect on pain intensity, self-experienced disability, and lumbar fatigability. Spine (Phila Pa 1976) 1999; 24: 1034-42.

28. Tokizawa Y, Tsujimoto T, Inoue T. Duration of venodilation for peripheral intravenous cannulation, as induced by a thermal stimulus on the forearm. Biol Res Nurs 2016 [Epub ahead of print].

29. van Bemmelen PS, Kelly P, Blebea J. Improvement in the visualization of superficial arm veins being evaluated for access and bypass. J Vasc Surg 2005; 42: 957-62.

30. Roberge RJ. Venodilatation techniques to enhance venepuncture and intravenous cannulation. J Emerg Med 2004; $27: 69-73$. 